\title{
Quality 4.0 for Processes and Customers
}

\author{
DOI: 10.12776/QIP.V25I3.1609
}

\author{
Anastasia Efimova, Petr Briš
}

Received: 2021-09-10 Accepted: 2021-10-29 Published: 2021-11-30

\begin{abstract}
Purpose: Considering the speed of technological development towards the Industry 4.0 era the change is necessary for managerial aspects in industrial companies. In this paper an attempt is made to understand the influence of Industry 4.0 technologies on the Quality 4.0 concept better.

Methodology/Approach: Two aspects were analysed in order to achieve the goal - the influence of Industry 4.0 on quality management and the influence of Quality 4.0 on customer satisfaction. The paper is based on a literature review and a pilot study based on questionnaires prepared for research purposes.

Findings: It was found out that the emergence of new technologies is beneficial for Quality Management processes and customer satisfaction. Moreover, the influence is greatly described by the amount of data now available for analysis. However, as the concept of Quality 4.0 is in its infancy, the necessary change is still required.

Research Limitation/Implication: As the research was conducted in the Czech Republic, the results are limited according to the territory. Also, the study was based on the literature review available from SCOPUS and WoS databases in English, thus further studies of available literature in other languages might be needed.
\end{abstract}

Originality/Value of paper: Although the quality tools that are used in Quality 4.0 are already known and accepted the influence of advanced technologies on quality management is not clear. In this paper an attempt is made to understand the influence.

Category: Research paper

Keywords: TQM; lean six sigma; industry 4.0; quality 4.0 


\section{INTRODUCTION}

In the contemporary world with the constantly increasing speed of change and technological advancement, many companies face the challenge of changing the existing methodologies and practices accordingly. With its first introduction in 2011, the term Industry 4.0 became an inseparable part of industrial life, thus influencing not only industrial processes but also the management of organizations of all types. This has led to the fact that nowadays managerial systems that have been used and proved their consistency are currently changing in order to be better integrated into the technological environment. As one of the important aspects of any business, quality management is also changing towards the Industry 4.0 era.

The quality management that integrates Industry 4.0 technologies is lately called Quality 4.0. However nowadays there is no universally accepted term for Quality 4.0, this term usually includes the usage of quality tools combined with new technologies characteristic for Industry 4.0, such as Big Data, Internet of things, etc.

Although the quality tools that are used in Quality 4.0 are already known and accepted the influence of the advanced technologies on quality management is not clear. The confluence of quality tools and Industry 4.0 technologies is considered to be beneficial (Chiarini, 2020), but the shift in quality management is not yet settled.

In this paper, an attempt is made to understand the influence of Quality 4.0 on quality management and to identify the key aspects of the conjunction of Industry 4.0 and existing quality approaches. As quality methodologies here, Total Quality Management (TQM) and Lean Six Sigma (LSS) were analysed as they have always been connected with technologies (especially for data gathering) and they are often (however not always) considered to be interrelated and interconnected as a part of the same organizational system (Salah and Rahim, 2019). Moreover, TQM is based on the principles of ISO 9001, the common patterns might be discovered and thus, the analysis of TQM was performed in this paper, along with the tools used to optimize them. However, this issue requires further verification.

\section{METHODOLOGY}

This paper is based on a systematic literature review supported by questionnaires developed by authors with the purpose to better understand the concept of Quality 4.0 and to offer a Quality 4.0 framework for successful implementation of Industry 4.0 tools for quality management in industrial companies.

The research is aimed to answer 2 research questions and to form the Quality 4.0 framework model based on the answers. The research questions are:

RQ1: How does Industry 4.0 influence quality management? 
RQ2: Could Industry 4.0 technologies improve customer satisfaction from the quality point of view?

The search for the answer to the research questions was conducted in 3 stages.

First, the literature review with the purpose to systemize the existing information on Quality 4.0 was conducted and the relevant articles were chosen. The search comprised the following terms "Quality 4.0", "TQM and Industry 4.0" and "LSS and Industry 4.0". The result was 12 articles found in research databases. The following step was the choice of exclusion criteria for the search. The exclusion criteria included articles written not in English, articles not connected with the research topic, non-availability of the article. Only articles published in scientific journals and conference proceedings were included. The search was conducted in Scopus and WoS databases. As the result, only 7 articles were included in the final literature review analysis part. Based on the systematic literature review the key aspects of Quality 4.0 were proposed connected with the change of quality management towards Quality 4.0 and the customer satisfaction.

The second stage was the pilot study aimed at a better understanding of the situation from the point of view of existing companies. Thus, an attempt to understand the current customer satisfaction was conducted based on the following and considering customer requirements. Then, the possibility to improve customer satisfaction was analysed from the theoretical point of view based on the systematic literature review. In this part, a survey that gathered 113 answers from companies in the Czech Republic was applied. To gather the data, the survey was developed and sent to 300 companies and as 113 answers were obtained the response rate is $37.7 \%$. The choice of companies was random. The companies of different sizes took part in the survey, $40.5 \%$ were large companies, $21.6 \%$ were medium companies and $37.8 \%$ were small companies. Companies that participated in the survey were from manufacturing (42\%), services $(20 \%)$, sales $(13 \%)$ and others, as well as companies working in several sectors of economy.

The third stage was aimed at estimating the influence of Industry 4.0 on existing quality management practices. The companies in the Czech Republic were asked to estimate the influence of Industry 4.0 technologies and the acceptance of different technologies was estimated. The data was gathered in another survey where40 companies participated. The gathered data was used to answer the RQ1 and provided additional information for the understanding of Quality 4.0.

Further, the gathered data was systemized and analysed from the point of view of the stated research questions.

\section{LITERATURE REVIEW}

The amount of technologies is growing, so is the amount of customer demands and speed of market competition. This sets a problem for industrial companies of 
how to adapt to everchanging complexity and to stay on the market. Different companies are looking for different ways to improve competitiveness and increase income. One of the ways is to adapt the existing quality management to the developing environment.

Contemporary studies of Industry 4.0 increase together with the interest towards the new concept. Industry 4.0 is interesting not only for managers from the managerial point of view but also for scientists from the theoretical point of view and conceptualization. This has led to the increasing number of attempts to develop theories on adaptation (Rossini et al., 2019), make an assessment (Yeen Gavin Lai et al., 2019), analyse (Leyh, Martin and Schaeffer, 2017), propose the implementation (Sony, 2017) and conceptual framework (Salkin et al., 2018), etc. This is because society has realized the necessity of change in development both in everyday and industrial life.

One of the most important managerial skills for every company that is connected with company success is quality management. Quality management is aimed at achieving high-quality results (Carvalho et al., 2021). Many companies are successfully using TQM and LSS that let them improve their manufacturing processes and services. In the contemporary world quality management is changing together with the world to be better integrated with technologies of Industry 4.0 and to create a new Quality approach that could be called Quality 4.0.

\subsection{Industry 4.0}

The constantly changing environment and the development of technologies have led to the emergence of a new concept of understanding the industrial processes as the next industrial revolution. This concept was called Industry 4.0.

Every industrial revolution brings the attempts of improving the existing manufacturing processes to better meet the market requirements (Yeen Gavin Lai et al., 2019). The current stage of the industrial revolution is connected with "machine intelligence, pervasive computing, affordable storage and robust connectivity" (Radziwill, 2018). With Industry 4.0 the improvements are provided by the development of Internet technologies allowing better data processing, Cyber and artificial intelligence concepts. "The fourth industrial revolution is a new level of organization of production and creation of high-tech products" (Ustinova, 2018).

With the rapid growth of the Internet, the necessity of better interaction with technologies and their advanced usage has appeared, such as data storage and processing. Considering the decreasing cost of technologies, the availability of change is accepted by the industrial world (Radziwill, 2018). Nowadays all kinds of products are "becoming "smart" (Rauch, Dallasega and Matt, 2016). This gave an impulse towards the faster development and the formation of a new industrial environment known as Industry 4.0. 
New fourth Industrial Revolution or Industry 4.0 has been announced by the German Government in 2011 at Hannover Fair (Salkin et al., 2018). Currently, the definition of Industry 4.0 varies depending on the country and/or industry. The common concept is to shift from a centralized way of production to a selfcontrolled and flexible way (Leyh, Martin and Schaeffer, 2017). The main idea of Industry 4.0 is to develop a Smart Factory (Yeen Gavin Lai et al., 2019) where the processes could be interconnected in a smart way.

With the growing individualized demand, product advancement and great interest towards the efficient usage of the resources, the need to coordinate and connect actions and information for industries is becoming increasingly important (Salkin et al., 2018). This gives momentum to the development of technologies that will be able to communicate and make simple decisions. The systems should be able to self-control and maintain good working conditions. The growing integration of these systems served as the reason for industrial change thus introducing the Industry 4.0 era.

Industry 4.0 has eight important technological developments: adaptive robotics, big data analytics, simulation, cyber-physical systems, industrial Internet, cloud systems, additive manufacture and networking (Salkin et al., 2018).

Apart from the technological aspect, Industry 4.0 also comprises a managerial aspect (Yeen Gavin Lai et al., 2019). It is important for managers and company leaders to shift their understanding of the technological world and to become more open-minded and forward-thinking. As the development is fast and it is complicated to predict what will gain more popularity and what will fail, it is becoming of increasing importance for managers to be able to foresee the development and welcome innovation to maintain the company's success, or to inspire the progress.

Moreover, as (Chiarini, 2020) indicate Industry 4.0 can influence also quality management. Thus, it is important to understand that the change affects many aspects of management in enterprises and requires a thorough understanding of the processes so that the introduction of Industry 4.0 shapes the development of the company positively and smoothly.

\subsection{Lean Six Sigma}

Lean Six Sigma appeared in 2000th as a junction of two successful methodologies - Lean and Six Sigma. Lean Six Sigma has the principle that: the activities that are critical to quality for the customer and have delays in time could be improved (George, 2002).

Lean as a term appeared from the book "The machine that changed the world" and became widespread due to the enormous success of Toyota company on the market in difficult times. Nowadays several definitions could be found on Lean depending on the field, application, etc. but all of the definitions have a common understanding of the Lean process as a smooth process with seven kinds of 
wastes being eliminated. "Lean management thinking is used to differentiate between waste and value within an organization" (Sony, 2017). These kinds of wastes are overproduction, over-processing, waiting, transportation, inventory, unnecessary motion, defects (Yeen Gavin Lai et al., 2019). Some authors also include unutilized talent in wastes (Gay, 2016).

Six Sigma first appeared in the Motorola company in 1980 (Adams, Gupta and Wilson, 2003). The main principle in Six Sigma is to control variability and decrease defects. The number of defects that is considered to be reasonable in Six Sigma is 3.4 per million opportunities. Six Sigma has a DMAIC circle as one of the main tools and that tool became also one of the basic tools of LSS.

Following the Six Sigma approach, LSS inherited tools from TQM while increasing the statistical component and introducing Lean tools and the Six Sigma belt system. Until now, the application of LSS is the most relevant and successful approach in many companies. However, considering the speed of development in the contemporary world, a need has appeared to adapt these concepts to the rapidly changing conditions of Industry 4.0.

\subsection{Total Quality Management}

Total Quality Management appeared also in Japan in the 1950s. It became the most popular approach to quality management (Dahlgaard-Park, 2011). It is aimed at constant improvement via quality increase. TQM is a management approach aimed at quality increase. The basic principles of TQM were gathered in ISO 9000 (Huffman, 2008). In 1989 the first book mentioning TQM has appeared, however similar approaches had been discussed in other books (Dahlgaard-Park, 2011).

In the book published in 1989, TQM is understood as an approach, that can be applied to ameliorate the "effectivencess and flexibility" of an organization as a unit (Dahlgaard-Park, 2011; Oakland, 1989). However, there are still different understanding of TQM the basic principles are similar: long-term orientation, although some results can be seen in a short-term perspective; inspiration and support of initiatives and teamwork, documentation of processes. Total Quality Management is a quality management approach that is aimed at continuous improvement (Tortorella, Silva and Vargas, 2018). In the given paper TQM is considered as an organizational approach that is aimed at quality improvement via tools, characteristic for this approach, especially connected with the usage of technologies for data gathering and data processing. The usage of TQM has already proved itself as being beneficial in many organizations. The approach itself does not provide any income but if to follows it properly the expensive processes can be found out and eliminated.

TQM approach is connected with data gathering and processing from the point of view of data assessment and analysis. Thus, the integration of contemporary technologies and the change in data processing might sufficiently influence TQM tools and principles. 


\subsection{Quality 4.0}

The emergence of new technologies is unavoidably connected with the methods that are used for quality control and assurance in an organization. This change in quality management influenced by the active shift towards Industry 4.0 technologies is called lately Quality 4.0. It is connected with the transparency provided by the influence of connectedness, intelligence and automation to quality tools (Chiarini, 2020).

However, Quality 4.0 is currently an emerging term and no standard has yet been accepted, several authors have already considered its influence in the industrial environment. Sütőová, Šooš and Kóča (2020) state that Quality 4.0 enhances the emergence of technologies and influences the quality in a positive way. However, Quality 4.0 is often considered to be connected with the effect of technologies on TQM (Carvalho et al., 2021; Chiarini, 2020; Nenadál, 2020), in this paper, LSS is also considered as an important part of Quality 4.0.

In his work (Radziwill, 2018) has presented several aspects of change in quality management following the American Society for Quality (ASQ). Future of Quality Report, that are the necessity of continuous learning for quality professionals, the shift in information transparency between organizations and supply chains and the expansion of customer requirements (Radziwill, 2018).

Quality 4.0 brings several benefits to quality management as an increase in speed and transparency, adaptation to new circumstances and continuous improvement between companies, and augmentation in awareness skills and intelligence (Milunovic Koprivica et al., 2019). Moreover, industrial transformation has direct influence on customer satisfaction, as it improves the customization of the product (Sütöová, Šooš and Kóča, 2020). The tendency to move towards the situation when computers using the benefits mentioned above will be able to assess and predict failures could have an important impact on quality management.

\section{RESULTS AND DISCUSSIONS}

\subsection{Influence of Industry 4.0 on Quality Management}

According to the literature review, the influence of Industry 4.0 is beneficial and could provide improvement to the existing quality management practices. However, as the initial search for the key terms resulted in 12 articles, it is not possible to state that the existing analysis is sufficient for the proper understanding of the confluence of Industry 4.0 and quality management. At the same time, some of the key points of influence of Quality 4.0 on the existing practices are summarized based on the literature review and are explained.

One of the most important peculiarities of Industry 4.0 is the amount of data that could be stored and processed. This data would influence many aspects of quality 
management and change them towards Quality 4.0, so the proper collection and storage of data are compulsory aspects for successful management. The technologies also could allow collecting data for quality management purposes in a more efficient way (Chiarini, 2020; Zonnenshain and Kenett, 2020). Quality management has always been data-driven and modern technologies could nothing but benefit the existing practices.

Another aspect that could be named here is the increase in process transparency. As some of the main failure factors of LSS are considered to be the difference between the project aim, the main goals of the company and the customer demand; lack of clear vision and a plan; the resistance to culture change (Albliwi et al., 2014), the quality management changed towards Quality 4.0 principles with increased transparency could be beneficial for many companies and help them to avoid unnecessary costs and failures. Smart sensors and Radio Frequency Identification (RFID) also impact process transparency (Chiarini, 2020). As the smart factory is based on the interconnection of the processes with transparency being one of the key success factors in the development, the communication not only between processes and projects in one organization but also interorganizational communication will be influenced greatly by this aspect. From the quality point of view, transparency would provide easier access to the information thus improving the connection with the data available for analysis and decision on future actions. Transparency is inseparably connected with the quality control phase, which is characteristic for both LSS and TQM, as it could lead to the reduction of errors and defects in processes (Chiarini, 2020).

Apart from transparency, credibility could also be improved with the usage of these technologies (Emblemsvåg, 2020). As these two factors could be connected in several ways, an increase in transparency usually has a positive impact on credibility. The customer and partner's understanding of the processes through the ability to better monitor and if necessary influence the flow should also have a positive impact on the quality management. Thus, the quality tools implemented in the process could be monitored and modified if necessary without losses, which should increase the credibility of both partners and customers as well as the suspicious workers participating in the process.

The prediction aspect of Quality 4.0 (Chiarini, 2020) also plays an important role in new quality management. One of the important aspects of quality management is to be data-driven (Zonnenshain and Kenett, 2020). Usage of Big Data and data analytics, especially with the usage of artificial intelligence, allows to store and process large amounts of data and to manage processes more effectively based on this data. Using the increased amount of data, managers would be more able to choose a proper strategy and implement a certain strategy. In LSS prediction aspect could influence improve phase and in the TQM act phase as the results could be better predicted based on the data. Quality 4.0 brings new technologies to optimize the quality management, when the automation and artificial intelligence could be used to improve the processes (Santos et al., 2021). The machine learning and artificial intelligence have great potential for the modelling 
and simulation of different processes and procideres, that could provide managers with necessary insights and benefit the process improvement. Thus, artificial intelligence could help to recognize mistakes in the process, communicate with

All the aspects mentioned above could also help to improve the situation in project-based industries as in these industries the legalism plays an important role the quality management, using the TQM and LSS are usually difficult to be introduced (Emblemsvåg, 2020). Thus, the augmented transparency, prediction and data collection, the simulation could influence the situation allowing the Quality 4.0 principles to be used in separate projects.

As many companies use the Industry 4.0 technologies in the Czech Republic to some level and the majority of them (93\%) find them useful, the influence of these technologies on quality management such as TQM and LSS are particularly interesting. In the pilot study, it was found out that the majority of companies, although consider LSS and Industry 4.0 an effective combination, the most widespread answer was as 3 out of 5 (where 5 is the most effective). At the same time $56.5 \%$ of respondents consider the influence of Industry 4.0 on LSS although being considerable, not very big (3 out of 5).

All the aspects mentioned above are inseparably connected with both new technologies of the Industry 4.0 era and quality management. Summarizing the information mentioned above it could be stated that the influence of contemporary technologies will change the quality management to become more autonomous and self-controlled. The data could be gathered by sensors and RFID, could be stored and analysed using Big Data technologies and simulated via simulation tools, thus creating a possibility of creating not only a smart factory where all the processes are interconnected but also smart quality management where some of the decisions on quality and/or quality tools could be made by the system created with the help of Internet of Things and Cyber Physical Systems. Thus, the answer to RQ1 is that the technologies are shifting the existing quality management generally by the increasing amount of data and data processing techniques.

\subsection{Influence of Quality 4.0 on Customer Satisfaction}

From the Quality 4.0 management customers could also benefit greatly. First of all, with the increased transparency the customer would be able to participate more in a process and customer requirements could be better satisfied. This will inextricably lead to customer credibility improvement and as a result customer loyalty could also be improved. Moreover, such technologies as 3D printing have already been using for customized products (Santos et al., 2021). Big Data is used for data collection and processing and augmented reality is used to demonstrate the interior spaces.

As it could be seen in Figure 1, the information gathered via questionnaire shows that $43.1 \%$ of companies follow the customer requirements in the maximum way 
possible. Although the amount of those who do not follow customer requirements at all is considerably law $0.9 \%$ (only one company chose this option), the improvement in this field could continue to serve as the benefit in the market competition.

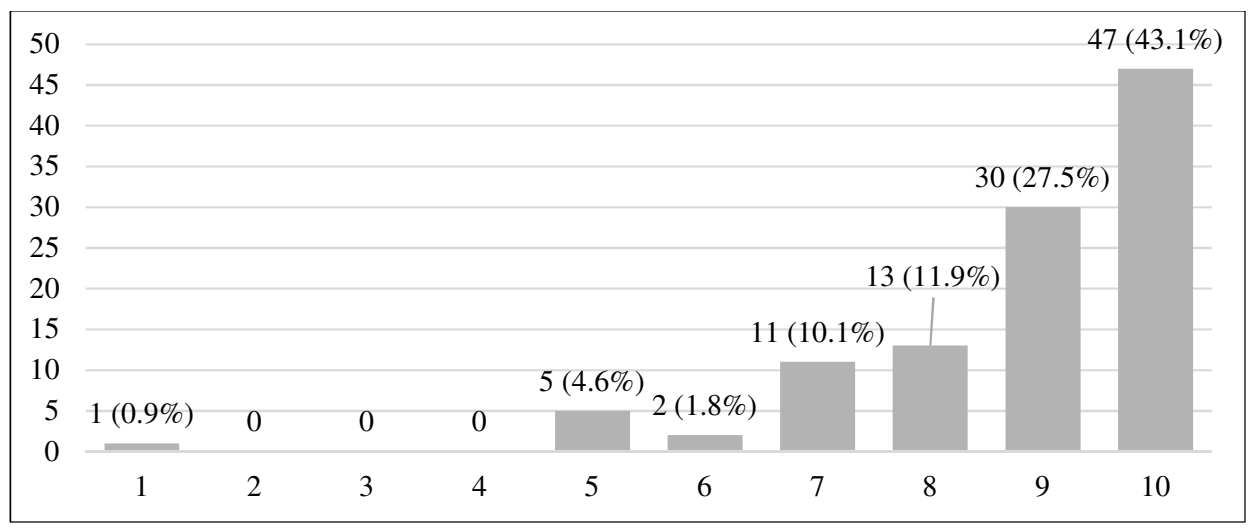

Figure 1 - How Much Do You Follow the Customer Requirements (1-min, 10-max)?

As Figure 2 depicts, almost 20\% of respondents answered that they consider customer requirements fully for their products. Moreover, out of 113 respondents, 97 answered that they consider customer requirements for their product not fully but in the major part. Considering the fact that the majority of answers, as could be seen in Figure 2, are on the range from 5 till 9, while only 6 answers out of 113 were on the scale from 1 to 4 , it could be concluded that the consideration of the customer requirements is an important issue for quality management in the Czech Republic.

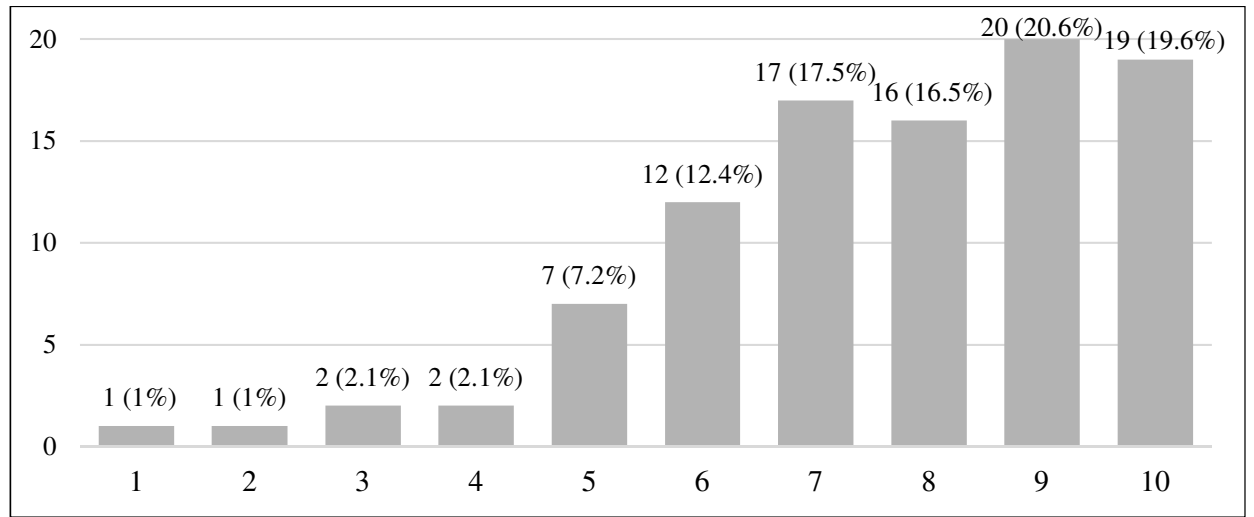

Figure 2 - How Much Do You Consider Customer Requirements for Your Product (1-min, 10-max)? 


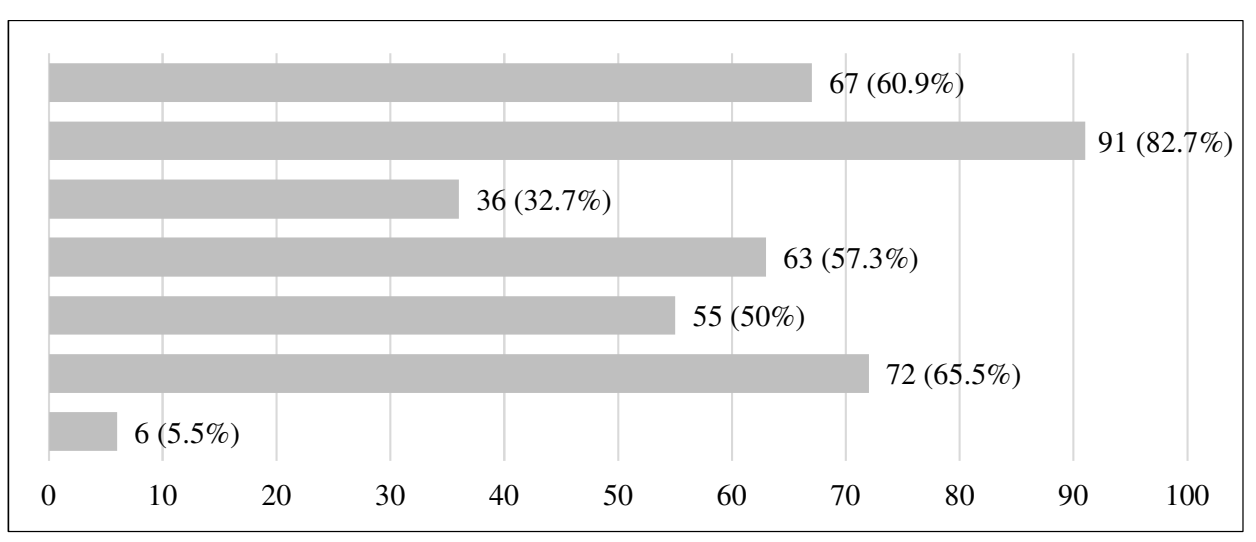

Figure 3 - Competitive Advantage

Another important aspect is that customer orientation is an advantage of a company against concurrence. That could be seen in Figure 3, where $65.5 \%$ of respondents choose this option as a competitive advantage.

This leads to the conclusion that the customer relations are a crucial issue for the companies' success, thus the change in customer relations could influence the company greatly. In his paper (Chiarini, 2020) has summarized the works stating that Industry 4.0 technologies will affect customer satisfaction by eliminating defects and adopting the product better to customer needs. The customer needs and requirements will be better processed using the emerging technologies and thus the final product will satisfy the customer better. To sum everything up, the potential connected with the Industry 4.0 technologies should contribute to a positive development of the customer relations and strengthen of the positive cooperation.

\section{CONCLUSIONS}

As Industry 4.0 technologies influence industrial life-changing the future of existing practices and theories there is a need to better understand the direction of the change in all the fields. This paper is aimed at understanding the change of quality management towards Quality 4.0. The paper was structured as a mixture of literature review and questionnaire analysis to better understand and analyse the situation.

In order to answer the aim of the paper two research questions were identified at the beginning of the research, namely how does Industry 4.0 influence quality management and if Industry 4.0 technologies could improve customer satisfaction from the quality point of view? The questions were answered via systematic literature review and pilot survey based on the questionnaire.

It was found out that the influence of Industry 4.0 on quality management is generally due to the amount of data and its availability. Through the data, transparency, credibility, prediction and control are provided. As the amount of 
data is growing and the technologies allow to analyse and store it better, the quality specialists have an opportunity to improve their tools to provide better success for their companies. Apart from Big Data and Big Data analytics, other important technologies for quality management, that promise the biggest amount of benefits are simulation, that, using the machine learning could be further advances. Artificial intelligence, that might support both production and services, could also provide quality managers with benefits necessary for Quality 4.0.

Another aspect is customer satisfaction with is considered to be one of the most important factors for company success and its connection with the quality management change. It was noted that technological advancement could improve the relationships between companies and their clients as the personification of products and increase in credibility might be improved with Quality 4.0. Moreover, as quality tools, in general, could be ameliorated, the number of defects could be decreased - this could also be considered as an opportunity to augment customer satisfaction.

Thus, the influence of technological advancement towards the Industry 4.0 era promises a positive impact on the quality tools as it provides better data for both processes and customers. However, the issue of Quality 4.0 is still in its infancy and the necessary changes would require some recourses from companies, the benefits from technologies for LSS and TQM could provide competition advancement for industrial firms.

\section{ACKNOWLEDGEMENTS}

Authors are thankful to the Internal Grant Agency of Tomas Bata University in Zlin No. IGA/FaME/2020/009 "Optimalizace procesů a znalostní informační systémy jako podpora podniků v Industry 4.0 ” for financial support to carry out research.

\section{REFERENCES}

Adams, C., Gupta, P. and Wilson, C., 2003. Six Sigma deployment. Boston: Butterworth-Heinemann.

Albliwi, S., Antony, J., Abdul Halim Lim, S. and Van der Wiele, T., 2014. Critical failure factors of Lean Six Sigma: a systematic literature review. International Journal of Quality \& Reliability Management, [e-journal] 31(9), pp.1012-1030. DOI: 10.1108/IJQRM-09-2013-0147.

Carvalho, A., Enrique, D., Chouchene, A. and Charrua-Santos, F., 2021. Quality 4.0: An Overview. Procedia Computer Science, [e-journal] 181, pp.341-346. DOI: 10.1016/j.procs.2021.01.176. 
Chiarini, A., 2020. Industry 4.0, quality management and TQM world. A systematic literature review and a proposed agenda for further research. The TQM Journal, [e-journal] 32(4), pp.603-616. DOI: 10.1108/TQM-04-2020-0082.

Dahlgaard-Park, S.M., 2011. The quality movement: Where are you going?. Total Quality Management \& Business Excellence, [e-journal] 22(5), pp.493516. DOI: 10.1080/14783363.2011.578481.

Emblemsvåg, J., 2020. On Quality 4.0 in project-based industries. The TQM Journal, [e-journal] 32(4), pp.725-739. DOI: 10.1108/TQM-12-2019-0295.

Gay, C., 2016. 8 Wastes of Lean Manufacturing | MachineMetrics. Machinemetrics, [online] 25 January 2016. Available at: $<$ https://www.machinemetrics.com/blog/8-wastes-of-leanmanufacturing\#: :text=Non\%2DUtilized $\% 20$ Talent,employee $\% 20$ talent $\% 20$ is $\%$ 20being\%20utilized> [Accessed 24 June 2020].

George, M., 2002. Lean Six Sigma: combining Six Sigma quality with lean speed. New York: McGraw-Hill.

Huffman, A., 2008. Six Sigma, TQM, Lean?. Quality Digest [online]. 03 January. Available at: <https://www.qualitydigest.com/inside/six-sigmaarticle/six-sigma-tqm-lean $>$ [Accessed 05 April 2021].

Leyh, C., Martin, S. and Schaeffer, T., 2017. Industry 4.0 and Lean Production A Matching Relationship? An analysis of selected Industry 4.0 models. In: FedCSIS (Federated Conference on Computer Science and Information Systems), Proceedings of the 2017 Federated Conference on Computer Science and Information Systems. Prague, Czech Republic, 03-06 September 2017. New York: IEEE. pp.989-993.

Milunovic Koprivica, S., Maric, A., Ristic, O. and Arsovski, S., 2019. Social Oriented Quality: From Quality 4.0 Towards Quality 5.0. Proceedings on Engineering Sciences, 1(2), pp.405-410. DOI: 10.24874/PES01.02.038.

Nenadál, J., 2020. The New EFQM Model: What is Really New and Could Be Considered as a Suitable Tool with Respect to Quality 4.0 Concept?. Quality Innovation Prosperity, [e-journal] 24(1), pp.17-28. DOI: 10.12776/qip.v24i1.1415.

Oakland, J.S., 1989. Total Quality Management. Oxford: Butterworth Heinemann.

Radziwill, N., 2018. Quality 4.0: Let's Get Digital - The many ways the fourth industrial revolution is reshaping the way we think about quality. Quality Progress, ASQ, pp.24-29. Available at: <https://arxiv.org/abs/1810.07829v1> [Accessed 05 April 2021].

Rauch, E., Dallasega, P. and Matt, D., 2016. The way from Lean Product Development (LPD) to Smart Product Development (SPD). Procedia CIRP, [ejournal] 50, pp.26-31. DOI: 10.1016/j.procir.2016.05.081. 
Rossini, M., Costa, F., Tortorella, G. and Portioli-Staudacher, A., 2019. The interrelation between Industry 4.0 and lean production: an empirical study on European manufacturers. The International Journal of Advanced Manufacturing Technology, 102(9-12), pp.3963-3976. DOI: 10.1007/s00170-019-03441-7.

Salah, S. and Rahim, A., 2019. Six Sigma and TQM. In: S. Salah and A. Rahim, eds. 2019. An Integrated Company-Wide Management System. Cham: Springer International Publishing. pp.39-47. DOI: 10.1007/978-3-319-99034-7_3.

Salkin, C., Oner, M., Ustundag, A. and Cevikcan, E., 2018. A Conceptual Framework for Industry 4.0. In: A. Ustundag and E. Cevikcan, eds. 2018. Industry 4.0: Managing The Digital Transformation. Cham: Springer Series in Advanced Manufacturing, Springer International Publishing. pp.3-23. DOI: 10.1007/978-3-319-57870-5_1.

Santos, G., Sá, J.C., Félix, M.J., Barreto, L., Carvalho, F., Doiro, M., Zgodavová, K. and Stefanović, M., 2021. New Needed Quality Management Skills for Quality Managers 4.0. Sustainability, [e-journal] 13(11), 6149. https://doi.org/10.3390/su13116149.

Sony, M., 2017. Industry 4.0 and lean management: a proposed integration model and research propositions. Production \& Manufacturing Research, [ejournal] 6(1), pp.416-432. DOI: 10.1080/21693277.2018.1540949.

Sütőová, A., Šooš, L. and Kóča, F., 2020. Learning Needs Determination for Industry 4.0 Maturity Development in Automotive Organisations in Slovakia. Quality Innovation Prosperity, [e-journal] 24(3), pp.122-139. DOI: 10.12776/qip.v24i3.1521.

Tortorella, G., Silva, E. and Vargas, D., 2018. An empirical analysis of Total Quality Management and Total Productive Maintenance in Industry 4.0. In: Proceedings of the International Conference on Industrial Engineering and Operations Management. Pretoria, Johannesburg, South Africa, 29 October - 1 November 2018. IEOM Society. pp. 742-753. Available at: <http://ieomsociety.org/southafrica2018/papers/186.pdf> [Accessed 05 April 2021].

Ustinova, L., 2018. Managing the promotion of new developments based on digital technologies. St. Petersburg State Polytechnical University Journal: Economics, 11(4), pp.100-110. DOI: 10.18721/JE.11407.

Yeen Gavin Lai, N., Hoong Wong, K., Halim, D., Lu, J. and Siang Kang, H., 2019. Industry 4.0 Enhanced Lean Manufacturing. In: 8th International Conference on Industrial Technology and Management (ICITM). Cambridge, United Kingdom, United Kingdom, 02-04 March 2019. pp.206-211. IEEE. DOI: 10.1109/ICITM.2019.8710669.

Zonnenshain, A. and Kenett, R., 2020. Quality 4.0- the challenging future of quality engineering. Quality Engineering, [e-journal] 32(4), pp.614-626. DOI: 10.1080/08982112.2019.1706744. 


\section{ABOUT AUTHORS}

Anastasia Efimova ${ }^{0000-0002-7930-7026}$ (A.E.) - Ph.D. student, Faculty of Management and Economics, Tomas Bata University in Zlin, Zlin, Czech Republic, e-mail: efimova@utb.cz.

Petr Brišs ${ }^{0000-0001-7027-1648}$ (P.B.) - Assoc. Prof., CSc., Faculty of Management and Economics, Tomas Bata University in Zlin, Zlin, Czech Republic, e-mail: bris@utb.cz.

\section{AUTHOR CONTRIBUTIONS}

Conceptualization, A.E. and P.B.; Methodology, A.E.; Formal analysis, A.E.; Resources, A.E. and P.B.; Original draft preparation, A.E.; Review and editing, A.E.; Supervision, P.B.; Funding acquisition, A.E.

\section{CONFLICTS OF INTEREST}

The authors declare no conflict of interest. The funders had no role in the design of the study; in the collection, analyses, or interpretation of data; in the writing of the manuscript, or in the decision to publish the results. 